\title{
BMJ Open Barriers to smoking cessation: a qualitative study from the perspective of primary care in Malaysia
}

\author{
Kooi-Yau Chean, ${ }^{1}$ Lee Gan Goh, ${ }^{2}$ Kah-Weng Liew, ${ }^{1}$ Chia-Chia Tan, ${ }^{1}$ \\ Xin-Ling Choi, ${ }^{1}$ Kean-Chye Tan, ${ }^{1}$ Siew-Ting Ooi ${ }^{3}$
}

To cite: Chean K-Y, Goh LG, Liew K-W, et al. Barriers to smoking cessation: a qualitative study from the perspective of primary care in Malaysia. BMJ Open 2019;9:e025491. doi:10.1136/ bmjopen-2018-025491

- Prepublication history for this paper is available online. To view these files, please visit the journal online (http://dx.doi. org/10.1136/bmjopen-2018025491).

Received 17 July 2018 Revised 17 April 2019 Accepted 18 June 2019

Check for updates

(C) Author(s) (or their employer(s)) 2019. Re-use permitted under CC BY-NC. No commercial re-use. See rights and permissions. Published by BMJ.

1Department of Family Medicine, RCSI \& UCD Malaysia Campus, Penang, Malaysia ${ }^{2}$ Department of Family Medicine, National University Health System, Singapore, Singapore 3University of Dublin Trinity College, Dublin, Ireland

Correspondence to Dr Kooi-Yau Chean; kychean@rcsiucd.edu.my, kychean@hotmail.com

\section{ABSTRACT}

Objectives This qualitative study aims to construct a model of the barriers to smoking cessation in the primary care setting.

Design Individual in-depth, semistructured interviews were audio-taped, then verbatim transcribed and translated when necessary. The data were first independently coded and then collectively discussed for emergent themes using the Straussian grounded theory method.

Participants and setting Fifty-seven current smokers were recruited from a previous smoking related study carried out in a primary care setting in Malaysia. Current smokers with at least one failed quit attempts were included.

Results A five-theme model emerged from this grounded theory method. (1) Personal and lifestyle factors: participants were unable to resist the temptation to smoke; (2) Nicotine addiction: withdrawal symptoms could not be overcome; (3) Social cultural norms: participants identified accepting cigarettes from friends as a token of friendship to be problematic; (4) Misconception: perception among smokers that ability to quit was solely based on one's ability to achieve mind control, and perception that stopping smoking will harm the body and (5) Failed assisted smoking cessation: smoking cessation services were not felt to be user-friendly and were poorly understood. The themes were organised into five concentric circles based on time frame: those actionable in the short term (themes 1 and 2) and the long term (themes $3,4,5)$.

Conclusions Five themes of specific beliefs and practices prevented smokers from quitting. Clinicians need to work on these barriers, which can be guided by the recommended time frames to help patients to succeed in smoking cessation.

\section{INTRODUCTION}

Cigarette smoking harms almost every organ of the body resulting in premature death in half of all smokers, ${ }^{1}$ and unfortunately there are over one billion smokers in the world. ${ }^{2}$ The prevalence of ever having tried to quit smoking varies in different countries, for example, less than $20 \%$ of smokers in China and Malaysia reported recent attempts to

\section{Strengths and limitations of this study}

- As a qualitative study from the primary care perspective, this paper contributes to the limited literature available on smokers' lived experiences of their attempts to quit smoking.

- A diversity of participants from different races and from both high and low nicotine dependence were recruited.

- The use of in-depth qualitative methods allowed detailed account of smokers' experience in smoking cessation.

- Focus group interview was not performed in this study because of participant reluctance and hence the opportunity to observe the interaction among participants was unavailable.

quit. ${ }^{3}$ Additionally, the estimated number of attempts before quitting successfully varied widely, ranging from 6.1 to $142 .{ }^{4}$ In those who tried to quit smoking, the abstinence rate at 6 months is only $3 \%-5 \%$ among those who selfquit $^{5}$ and $19 \%-33 \%$ among those who opt for pharmacotherapy. ${ }^{6}$ We must therefore take an in-depth look from a variety of perspectives to understand the reasons contributing to failures in smoking cessation.

Eighty per cent of smokers in the world live in developing countries. ${ }^{2}$ Hence, studies related to quit smoking behaviours conducted in the relevant cultural and socioeconomic settings of developing countries are needed.

Malaysia is a developing country with a complex society-ethnically, linguistically, culturally and religious faiths. It has three major races of Malays, Chinese and Indians, with numerous indigenous ethnic groups. Such ethnic and cultural diversity may make smoking cessation a more complicated task for medical practitioners.

Approximately $22.8 \%$ of Malaysians smoke. ${ }^{7}$ The smoking rate for adult males is $43 \%^{7}$ and for adult females is $1.4 \% .^{7}$ The high prevalence of current smokers is associated with males, Malays, the rural population, 
government servant and those with low educational background. $^{7}$ By ethnic distribution, the prevalence of smokers was the highest among the Malays, followed by Indians, then Chinese. ${ }^{7}$ There are no statistics available for indigenous groups. Over the past 12 months, 52.3\% of current smokers in Malaysia made an attempt to quit smoking. ${ }^{7}$ Overall, less than $10 \%$ of current smokers visited a healthcare provider with $75.4 \%$ of them having been advised to quit smoking. ${ }^{7}$

This study was triggered by the results of one of our smoking related study, 'Assessing Airflow limitation Among Smokers in a Primary Care Setting' (https:// doi.org/10.21315/mjms2018.25.3.8). In that study, the authors found a high prevalence of airflow limitation among smokers and from it implied urgency in helping smokers to quit smoking. So the triggered research question is what barriers prevented smoking cessation from take place.

This study aims to explore barriers to quitting smoking from the perspective of primary care. We chose a qualitative study because 'this will be able to capture expressive information about beliefs, values, feelings, and motivations that underlie the behaviour ${ }^{8}$ of participants. The process of comparing and exploring smokers' answers to our open questions can also potentially lead us to 'discover' new patterns of information regarding barriers to quitting smoking in this unique society. Primary care providers with "whole person medical practice ${ }^{9}$ have the most opportunities to help smokers to quit smoking. Identifying barriers to quitting is an important step in both the 5 As approach (Ask, Advise, Assess, Assist and Arrange) and the 5Rs approach (Relevance, Risks, Rewards, Roadblocks and Repetition $)^{10}$ in brief intervention. Our study will help primary care practitioners in smoking cessation counselling.

\section{METHODS}

\section{Study design}

A grounded theory study method was chosen as this will allow a new understanding of the barriers to smoking cessation from the primary care perspective. This study method may be defined as a 'general method of comparative analysis' ${ }^{11}$ without pre-existing conceptualisation to uncover social processes. A theory is then constructed through the data analysis, ${ }^{12}$ which is presented.

\section{Setting and sample}

This study was conducted in Penang, Malaysia during January and February 2017. We recruited participants using purposive sampling, which is a 'non-probability' and a criterion based sampling technique. ${ }^{13}$ Subjects were selected based on certain characteristics, which will enable a holistic and in-depth exploration of the research topic. From a previous smoking related study in 20162017, the authors had a ready list of 191 participants with at least one failed quit attempts. Their demographic profile, smoking history and Fagestrom test for nicotine dependence level were also available. We contacted the eligible participants by telephone to explain the purpose and the nature of the study. Participants had the option to meet with investigators at RCSI \& UCD Malaysia Campus or an alternative preferred location (including their homes) for an interview. Sample size was determined on the basis of theoretical saturation. Subjects from both high nicotine dependence (Fagerstrom score $6-10)^{14}$ and low nicotine dependence (Fagestrom score 1-5) ${ }^{14}$ were included. Twelve invited smokers refused to participate in the study. Eight of them did not give any reason and four stated that they were too busy. We did not manage to organise any focus group discussion as intended because our participants felt that they were too shy to speak in such a group format. In the smoking cessation barriers model presented in this paper, we defined short-term potential modifiable strategies as less than 3 months of smoking abstinence ${ }^{1516}$ and potential long term strategies as 12 months or longer of smoking abstinence ${ }^{1718}$ based on study designs reported in the current literature (2015 to 2019) obtained from PubMed searches.

\section{Data collection}

Informed written consent was obtained from all participants. Fifty-seven one-to-one individual in-depth interviews were conducted by a team of six researchers. The team comprised of two family physicians and lecturers-K-CT (male) and K-YC (female) from RCSI \& UCD Malaysia Campus; three medical graduates awaiting internship posting-K-WL (male), C-CT (female) and $\mathrm{X}$-LC (female) and one medical student-S-TO (female) from Ireland. K-YC conducted two pilot interviews and provided training in conducting the interviews for the rest of the team. None of the interviewers were known to the participants. The technique used by interviewers was one-to-one, open-ended questions, semistructured format, conversational with intense probing for deeper meaning and understanding of the responses. Interviewers followed an interview guide (box 1) which was consistent with the concept of being 'open' and 'discovery' aiming to construct a particular theory. The initial question asked was open-ended to facilitate participants to describe, to

\section{Box 1 Interview guide}

Opening question:

Please share with us your experience in quitting smoking in the past. Prompts:

How many times have you tried/did you try (before you succeeded)? When was it?

How long did you stop for?

How did you stop smoking?

What caused you to resume smoking after stopping?

What makes the process difficult?

What is your reflection on this experience? What did you learn from this experience?

Would you like to say something we haven't talked about and that is important for you? 
reflect and to express values in their own words. Subsequent questions were determined by both the participants' response and the predetermined questions in the interview guide (box 1). Questions were phrased in a way to get lengthy, detailed answers from participants.

The interviews were conducted in participants' preferred language which included English, Malay, Mandarin and Hokkien dialect. The duration of interviews took between 20 and $60 \mathrm{~min}$. The interviews were audio-recorded and transcribed verbatim. Non-English interviews were translated to English by the respective interviewers.

The interviewers met up with the participants within 2 weeks of the interviews to verify the accuracy and to correct any transcription errors. At the second encounter, participants were encouraged to provide additional information if they wished.

\section{Data analysis}

Data was anonymised and transcribed. All six researchers started line-by-line open coding independently to ensure that the analysis was holistic and inductive. The researchers then met for axial coding and clustering to develop master headings and subsequently higher categories. Fragmented codes were linked by using the techniques of constant comparison, continual checking and clustering of emerging themes to formulate a theoretical model. ${ }^{19}$ QDA Miner Lite software ${ }^{20}$ was used to assist with code frequency analysis, coding retrieval and Boolean text search.

\section{Patient and public involvement}

No patient or public were involved in the design, recruitment and conduct of the study.

\section{RESULTS}

We interviewed 57 participants. Table 1 shows the participants' demographic characteristics in detail.

\section{Themes generated from grounded theory}

Theme 1: Personal and lifestyle factors

A majority of abstinent participants were unable to resist temptation cues when challenged. Their smoking relapses were attributed to the influence of friends who smoked in social activities or work places.

I felt it was because I mingled with friends who are all smokers. So, if I am the only person who has the plan to stop smoking and mix with friends who are still smoking, that is why... because the cigarette is exposed. I don't have any choice. (Participant 17)

Participants conceded that relapses in smoking cessation were often related to impaired capacity for self-control and lack of intrinsic motivation.

'Control... no power of control. Self-control is weak, rather weak. (Participant 13)
Table 1 Demographic characteristics of participants $(n=57)$

\section{Demography characteristics}

\begin{tabular}{ll}
\hline $\begin{array}{l}\text { Age, years, mean (SD) } \\
\text { Range }\end{array}$ & $58(10.8)$ \\
Gender, $\mathrm{n}(\%)$ & $40-82$ \\
\hline Male & $56(98 \%)$ \\
\hline Female & $1(2 \%)$ \\
\hline Ethnicity, $\mathrm{n}(\%)$ & $15(29.4 \%)$ \\
\hline Malay & $32(62.7 \%)$ \\
\hline Chinese & $4(7.8 \%)$ \\
\hline Indian & \\
\hline Education level, $\mathrm{n}(\%)$ & $21(36.8 \%)$ \\
\hline Primary education & $19(33.3 \%)$ \\
\hline Lower secondary & $14(24.6 \%)$ \\
\hline Upper secondary & $3(5.3 \%)$ \\
\hline Tertiary & \\
\hline Fagestrom score, $\mathrm{n}(\%)$ & $8(14.0 \%)$ \\
\hline High addiction (8-10) & $14(24.6 \%)$ \\
\hline Moderate (5-7) & $20(35.1 \%)$ \\
\hline Low to moderate addiction (3-4) & $15(26.3 \%)$ \\
\hline Low addiction (0-2) & \\
\hline Marital status, $\mathrm{n}(\%)$ & $10(17.4 \%)$ \\
\hline Single & $43(75.4 \%)$ \\
\hline Married & $3(0.05 \%)$ \\
\hline Divorced & $1(0.02 \%)$ \\
\hline Widowed & \\
\hline Previous attendance at smoking \\
cessation clinics, $\mathrm{n}(\%)$
\end{tabular}

Some participants related that the decision to resume smoking was rather impulsive.

Yes, it is a mistake. Because I was already not looking for (cigarette) that time, I already was not craving, but just 'try, try'. After then, it was like learning again, learning again the taste slowly, it was like normal... tried to discipline ah, err. After 1 week, it was very hard, definitely very hard, (I) want to find a cigarette, then (I) must resist, resist the temptation until 2 weeks then it went. By week 3, I feel that even the smells smoke from other smokers make me not comfortable; not because I was craving for a cigarette, but it was because it was like 'stinky'. After then, gradually 1 month, 2 months, it is ok lah. It is stable. By third month and fourth month like that, definitely I was not looking (for a cigarette). After then, I started to have the urge for a cigarette, so I want to try again, so it was my fault. It was like 'play... play' smoke, smoke again, not because of addiction oh. (Participant 17) 
In addition, the withdrawal of extrinsic factors that motivated our participants to stop smoking was felt to be the reason for the resumption of smoking. For example, recovering after sickness, release from prison, no longer in a smoking free zone, no longer taking care of a sick relative or no longer being nagged.

I was admitted to ICU (intensive care unit) for five times in IJN (National Heart Institute). So I smoked again after my bypass, I resumed smoking. (Participant 28)

\section{Theme 2: Nicotine addiction}

Cigarettes contain highly addictive nicotine, and participants did report overpowering withdrawal symptoms on quitting.

...Stopped 1-2 months, I felt more tired...If I didn't smoke, I was not able to open my bowel, I became constipated.......If I smoked at night, I slept better. (Participant 26)

I was feeling difficult, breathless at times. I also noticed that I had chest discomfort which was more when I work. I had no choice but to smoke again. (Participant 51)

Psychological dependence was clearly highlighted by the pleasure they experienced from smoking. Participants described experiences which were strongly suggestive of psychological addiction to cigarette smoking, regardless if they realised it or not.

That actual problem is our mind, the brain... because why, you know? When we are not smoking, the brain will tell you: 'There are other smokers there, could you ask him for one cigarette? (Participant 37)

...because for smoker, you feel that something is missing. So, you tend to ask for a stick. Ask for a stick, you know. Then from then starts again. Two sticks... (Participant 41)

\section{Theme 3: Sociocultural norms}

Some participants expressed that the offering of cigarettes from friends and relatives was the main reason for their failure to quit. It was normal for smokers to offer their friends and relatives cigarettes as a sign of goodwill and a close relationship.

My friends... They offer and we don't refuse it. We take it as a token of friendship. (Participant 43)

In some participants, despite having informed their peers that they had quit smoking, they were still coerced into smoking. The peers gave them the impression that smoking a small amount of cigarettes would not affect their ability to quit smoking.

I actually managed to quit-roughly 3 months. After that, I went for a course in Bangi for a week. There, I had colleagues who smoke, they offered me. I said I didn't want (to smoke) because I've quitted. And they said, 'Never mind, only one... So he gave me, and I smoked. After that, after lunch, he offered me again. (Participant 9)

For Muslim participants, the withdrawal of social and religious motivation after Ramadan (Fasting month) also increased the tendency to relapse.

The month of 'puasa' (the fasting month), I was free for the 1 month. Don't want lah, I don't want to smoke in front of my family. Then, when it is during 'iftar', smoking will waste a lot of time. So, I let myself relax for 1 month. I wanted to rest during fasting month. For my lungs to cleanse it...After the fasting month, I started back but less (cigarette). Sometimes 3-4 sticks, 5-6 sticks. (Participant 23)

\section{Theme 4: Misconception}

Smoking cessation is a complex and dynamic process and most smokers make multiple attempts of reduction and abstinence. ${ }^{21}$ Some participants perceived smoking cessation as just a game of the mind.

...to quit smoking depends on will power. For me, this is a game of the mind. We set our mind, err, tomorrow, I don't want to smoke tomorrow, then I will not smoke tomorrow. (Participant 23)

I smoke for 'saja' (just for fun), not because of addiction. But, if it is due to emotional problems, up to here (point to his head); there are a lot of problems not solved, and the feeling is up to here (point to head), this is another experience, then there will be just cigarette only. When the mind is not calm, err, finish one stick then another, again and again. (Participant 17)

Patients usually trust their doctors and therefore take their doctors' recommendation seriously. Ideally, this advice would include cessation tips and the correction of false beliefs and misconceptions.

I stopped abruptly, so I felt breathless. Then my family brought me to the hospital ... Then the doctor scolded me, 'Did you want to die?' You cannot stop (smoking) completely all of a sudden. If you want to stop, you need to come to the hospital and meet with the MO (medical officer), the doctor, to get their advice... At least you have to smoke one a day. (Participant 9)

Some participants exaggerated or misinterpreted the effects of smoking cessation as harmful to health.

I stopped for a few months then I became frightened. My friends said once stopped, disease will come. Also, I saw my friend (who) died after stopping (smoking). (Participant 11)

There are side effects when stop smoking, after I stopped smoking, I was diagnosed with high blood 
pressure and had a heart attack as well. (Participant 28)

One participant who believed that secondhand smoke was more harmful than smoking itself.

If I breathe in secondhand smoke, it is more poisonous than if I smoke myself. (Participant 1)

It was interesting to also highlight the belief that smoking might in fact, be therapeutic.

I had that disease (Idiopathic thrombocytopenic purpura) for a long period, I did not know... I suffered from bleeding gum when I brushed my teeth, sometimes it happened spontaneously. So I resumed smoking. Once I started (smoking) ... the gum bleed stopped...smoking is good. (Participant 33)

One participant commented that hand-rolled tobacco leaves were less hazardous than commercial cigarettes.

People said 'rokok daun' (tobacco leaves) is better when compare to a cigarette. I cannot 'tahan' (stand) without smoking..., so, after discharged from the hospital, my friend recommended 'rokok daun' (tobacco leaves) to me. The smell is there...I tried it and I continue to smoke...At least, this 'rokok daun' is better, and I managed to stop the cigarettes. (Participant 49)

Interestingly, there were participants who developed defense mechanisms themselves to ward off the concept that smoking is dangerous/unacceptable. This was particularly true when the participants felt obliged to refrain from smoking in the presence of young children or other family members.

...Sometimes I smoke alone in my own room. But, I, err, I open the windows. My room has air-conditioner but I don't even turn it on... 'I turn on the fan to blow away all the smoke. (Participant 6)

\section{Theme 5: Failed assisted smoking cessation}

Some participants tried conventional methods (smoking cessation clinics, nicotine replacement therapy) as well as alternative methods such as electronic cigarettes in their attempts to quit smoking. Most participants expressed that pharmacotherapy was ineffective. This perhaps resulted in a negative impression towards the effectiveness of assisted smoking cessation.

Smoking cessation clinic does not work. I tried chewing the gum, no use. Not working at all. Whatever medications they gave to stop smoking did not work. (Participant 16)

I already bought the type of cigarettes, that 'blocked', I am not sure if you have heard that before. The one with three cigarettes that is like when you smoke, it has no taste. May be you can quit, but I cannot. I brought from the pharmacy. (Participant 18)

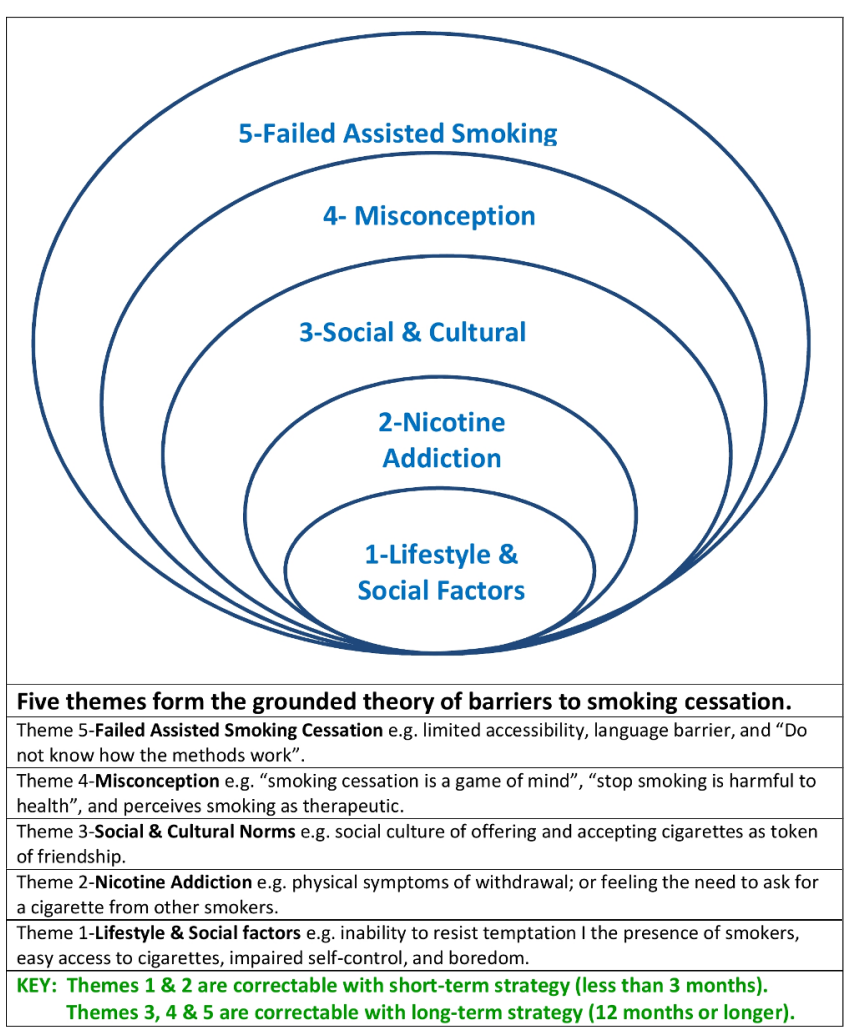

Figure 1 A grounded theory of barriers to smoking cessation.

Non-pharmacological factors also contributed to the dropout from smoking cessation clinics. These included the accessibility of the clinic and the language spoken. Language barriers were highlighted because of multiple languages spoken in Malaysia.

I have been to smoking cessation clinic two times. It is just too troublesome to keep going there. (Participant 27)

But I have gone there (stop smoking clinic). They were all Malay and my Malay is not very (good)... I did not really understand. (Participant 1 )

Some participants also noted that they did not know the methods available to quit smoking even though they were willing to try them. Participants implied that their medical practitioners did not convey nor educate them in the methods available to help them to quit smoking.

Doctors don't teach how to stop. And also nobody help you to stop. Do you think so? So, you don't know the way to stop. (Participant 24)

\section{A descriptive model from grounded theory}

Figure 1 presents a descriptive model showing the relationship among the five grounded theory themes of participants' perceived reasons for failed quit smoking attempts. Notes accompanying the diagram in figure 1 provided examples of each grounded theory theme.

The five themes are displayed as five concentric circles to show the relationship of the themes to one 
another. Theme 1 (Lifestyle \& Social Factors) describes the participants perceived the need to avoid presence of smokers, easy access to cigarettes, impaired self-control, and boredom' in order to avoid nicotine addiction (theme 2). Theme 3 (Social \& Cultural Norms) which includes 'offering and accepting cigarettes as token of friendship' have had great relapse consequences on abstinent smokers. Theme 4 (Misconception) relates smokers' lived experiences on why they continue to smoke. Some smokers perceive smoking as a 'game of the mind' and they can quit anytime they wish to do so; others continue to smoke because of the misconception that stopping smoking will be harmful to health. Theme 5 (Failed Assisted Smoking Method) describes failures in the healthcare delivery system as perceived by smokers. Participants interviewed in this study had negative experiences of the smoking cessation services received, such as 'limited accessibility', 'language barrier' and 'Do not know how the methods work'.

\section{Time frames for overcoming barriers to smoking cessation}

In this grounded theory study, we created a model of five themes of smoking abstinence barriers. Two were potentially surmountable in the short term (less than 3 months) and three were potentially surmountable in the long term (12 months or longer) time frames (figure 1).

\section{DISCUSSION}

Smoking cessation is a challenging human process for both patients and doctor alike. Despite many decades of trying, we are struggling to make a significant improvement in cessation rates. A 2014 systematic review of qualitative and quantitative literature by Twyman $e t a l^{22}$ on six vulnerable groups (low socioeconomic; indigenous; mental illness; homeless; prisoners and at risk youths) described three common cessation barriers. These were: smoking for stress management, lack of social support from health and other service providers and a high prevalence and acceptance of smoking in vulnerable communities.

Our study adds to what is known from Twyman $e t a l \mathrm{~s}^{22}$ review. New areas are covered namely; our participants were community based. Demographically, the mean age group (SD) was 58 (10.8); our participants comprise the three major races in Malaysia, with diverse cultural backgrounds. In addition, the uniqueness of the grounded theory method used in this study was that it produced the results on the lived experience of barriers to smoking cessation, which then formed the theory that explained the barriers to smoking cessation.

In Twyman et al's study, the duration of 'short term' and 'medium and long term' in the smoking cessation strategies was not defined. We have defined the time frames based on current literature namely, for short term as less than 3 months ${ }^{15}{ }^{16}$ and long term as 12 months or longer in smoking cessation strategies. ${ }^{1718}$ The two studies agree on lifestyle and individual factors as short-term abstinence strategies, and similarly on cultural factors as long-term abstinence strategies. Misconception as a theme was not identified in Twyman $e t$ als paper. We have classified this newly discovered theme as one that requires long-term strategy because the patients who made the remarks were in the precontemplative stage of change namely, smoking cessation 'as a game of the mind' and stopping smoking as harmful to health.

There are several conclusions to be taken from this study:

(1) Theme 3: Offering cigarettes to one another is perceived as a sign of friendship and this cigarette culture serves as an impediment to smoking cessation in this society. In China, offering cigarettes is a sign of mutual respect during social events. ${ }^{2324}$ It is customary for a subordinate to light a cigarette for his seniors. ${ }^{24}$ Smokers in our community will need to be taught methods of rejecting the offer of cigarettes and reassurance that declining an offer of a cigarette is not seen to be rude.

(2) Theme 3: Smokers find it easier to stop smoking during Ramadan due to the religion, cultural and environmental influences. ${ }^{25}$ Although many Muslim smokers $(97.7 \%)^{26}$ in Malaysia smoke fewer cigarettes during Ramadan, only $15 \%$ perceive Ramadan as a strong motivator to quit smoking ${ }^{27}$ and therefore most relapse after Ramadan. It is also known that such smoking behaviour changes during Ramadan are associated with those of higher incomes, high nicotine dependence and those who are not aware that smoking is 'haram' (forbidden). ${ }^{25}$ Ramadan should be seen as an excellent opportunity for the implementation of a religious-competent intervention to improve cessation rates.

(3) Theme 4: Our participants revealed a number of misconceptions which were considered to be different from those listed in the literature. ${ }^{28}$ For example, misinformation and misconceptions led them to believe that reduction in tobacco consumption is acceptable, but if they were to quit smoking entirely, it will cause disease. Secondhand smoking is perceived to be more harmful than active smoking and therefore they believe that in a smoking environment, active smoking is encouraged. In addition, false beliefs that smoking may be therapeutic or smoking with the fan on or hand-rolled cigarettes are less hazardous is present in this community. Therefore, clinicians should first assess and dispel the relevant false beliefs during counselling sessions.

(4) Theme 1 and Theme 2 interactively: To healthcare practitioners, tobacco smoking is regarded as an addiction. However, to patients, it is regarded as self-determined lifestyle choice. ${ }^{29}$ Such discrepancy was observed in this study. It has long been established that nicotine addiction is the biggest cause of failure in smoking cessation. Nicotine can be as addictive as heroin, cocaine or alcohol ${ }^{30} 31$ and as a result, attempts to quit smoking are often unsuccessful because of withdrawal symptoms including stress and weight gain. ${ }^{32}$ Nevertheless, our participants did not perceive addiction as the major factor of failure, instead they expressed overwhelmingly that quitting smoking 
is a 'game of the mind'. Smokers blamed themselves as having poor determination in that stopping smoking is a matter of how they control their mind. This finding is consistent with that of a recent quantitative study ${ }^{33}$ which showed that most smokers believe willpower is necessary or sufficient for quitting. Such belief in mind control as the tool to quit smoking undermines the use of formal cessation assistance. The failure to recognise symptoms of addiction of smoking renders smokers to 'not believe' in the usefulness of pharmacotherapy. ${ }^{34}$ The use of smoking cessation strategies in our setting has been low $^{35}$ and we believe such misconceptions contribute greatly to the failure of smoking cessation. Participants were reluctant to receive professional help and preferred to 'quit' by themselves. A national survey in 2016 in Malaysia revealed that nearly $80 \%$ of former smokers quit without any professional intervention. ${ }^{35}$ More work is needed to help smokers to accept that cigarette smoking is highly addictive and that nicotine addiction is very powerful. In addition, healthcare practitioners need to ensure sufficient patient knowledge to improve their confidence to acknowledge withdrawal symptoms and to focus more on the end result during the cessation process.

\section{LIMITATIONS}

The main limitation of this study is that only in-depth interviews and no focus group interviews were conducted. We did not organise any focus group interviews because the participants were too shy to speak in a group. While the opportunity to observe the interaction among the participants was lost, we managed to gain a more in-depth, detailed account of smokers' experience without them feeling inhibited to speak in a group.

Another possible limitation is selection bias. The highest education grade completed by the majority $(70.1 \%)$ of the participants was either primary school or lower secondary education and this could have resulted a 'less-educated-population'. Nonetheless, we think the data obtained in our study are sufficiently robust to describe reasons contributing to failures in smoking cessation in this community.

\section{IMPLICATIONS AND RECOMMENDATIONS}

We have provided suggestions for applications based on the grounded theory findings in the discussion above. We can use similar grounded theory design to explore theme 2 and theme 5 with the view of defining the extent of ignorance in the symptoms of nicotine addiction; misconceptions and patient concerns on service provision deficiencies and lack of user-friendliness.

In addition, the themes of this model serve as a checklist for clinicians when exploring barriers to smoking cessation. In particular, in step 4 of both the $5 \mathrm{~A}^{10}$ (assist) techniques and $5 \mathrm{R}^{10}$ (Roadblock) technique of brief intervention for smoking cessation so that appropriate action plan can be tailored accordingly. With all these efforts, hopefully, we could reach better smoking cessation rates.

\section{CONCLUSION}

Five themes of specific beliefs and practices prevented smokers from quitting. Clinicians need to work on these identified categories to help patients overcome barriers to smoking cessation guided by the time frames recommended by the authors. This study highlighted the importance of sociocultural environment and misconception as factors contributing to the failure to quit smoking in this community. Educating smokers to dispel their misbeliefs is crucial. Development of religiously and culturally competent interventions should be considered to reduce relapse rate.

Acknowledgements We thank all the participants in this study. We are grateful for their involvement and effort. We also thank Professor Paul Fogarty for his diligent copyediting of this article.

Contributors $\mathrm{K}-\mathrm{YC}$ conceived the idea. $\mathrm{K}-\mathrm{YC}$ and $\mathrm{LGG}$ contributed to the design of the study. K-YC, K-WL, C-CT, X-LC, K-CT and S-TO conducted the individual focus interview, translated and transcribed independently. K-YC, K-WL, C-CT, X-LC, $\mathrm{K}-\mathrm{YC}$ and S-TO carried out thematic analysis as a group and drafted the original manuscript. K-YC and LGG critically revised the manuscript. All authors provided approval of the final manuscript.

Funding The authors have not declared a specific grant for this research from any funding agency in the public, commercial or not-for-profit sectors.

Competing interests None declared.

Patient consent for publication Not required.

Provenance and peer review Not commissioned; externally peer reviewed.

Data sharing statement The data that support the findings of this study areavailable from the corresponding author, Chean $\mathrm{K}-\mathrm{Y}$ upon reasonable request.

Open access This is an open access article distributed in accordance with the Creative Commons Attribution Non Commercial (CC BY-NC 4.0) license, which permits others to distribute, remix, adapt, build upon this work non-commercially, and license their derivative works on different terms, provided the original work is properly cited, appropriate credit is given, any changes made indicated, and the use is non-commercial. See: http://creativecommons.org/licenses/by-nc/4.0/.

\section{REFERENCES}

1. Le Foll B, Pushparaj A, Pryslawsky Y, et al. Translational strategies for therapeutic development in nicotine addiction: rethinking the conventional bench to bedside approach. Prog Neuropsychopharmacol Biol Psychiatry 2014;52:86-93.

2. World Health Organisation. Tobacco: World Health Organisation. 2017. (updated May 2017) http://www.who.int/mediacentre/ factsheets/fs339/en/ (Accessed 20 Jan 2018).

3. Borland R, Li L, Driezen P, et al. Cessation assistance reported by smokers in 15 countries participating in the International Tobacco Control (ITC) policy evaluation surveys. Addiction 2012;107:197-205.

4. Chaiton M, Diemert L, Cohen JE, et al. Estimating the number of quit attempts it takes to quit smoking successfully in a longitudinal cohort of smokers. BMJ Open 2016;6:e011045.

5. Hughes JR, Keely J, Naud S. Shape of the relapse curve and long-term abstinence among untreated smokers. Addiction 2004;99:29-38.

6. Tobacco Use and Dependence Guideline Panel. Treating Tobacco Use and Dependence: 2008 Update. 6, Evidence and Recommendations. Rockville (MD: US Department of Health and Human Services. https://www.ncbi.nlm.nih.gov/books/NBK63943.

7. Institute for Public Health (IPH) 2015. National Health and Morbidity Survey 2015 (NHMS 2015). Vol. II. Non-Communicable Diseases, Risk Factors \& Other Health Problems: Ministry of Health Malaysia, 2015. 
8. Berkwits M, Inui TS. Making use of qualitative research techniques. $J$ Gen Intern Med 1998;13:195-9.

9. Stewart M. Reflections on the doctor-patient relationship: from evidence and experience. Br J Gen Pract 2005;55:793-801.

10. Ministry of Health Maldives. National Tobacco Cessation Toolkit (5A \& 5Rs) for all doctors and health professionals: Tobacco Prevention \& Control Program, Health Promotion and Chronic Disease Control Division of Health Protection Agency,and Tobacco Cessation Clinic, Dhamanaveshi, Male',Ministry of Health, Maldives. 2016 http://www. searo.who.int/maldives/documents/tobacco-cessation-toolkit.pdf? ua $=1$ (Accessed 27Jun 2018).

11. Samik-Ibrahim RM. Grounded Theory Methodology as the Research Strategy for a Developing Country. 2000;1.

12. Strauss A, Corbin J. Chapter 7: Grounded Theory Methodology: An Overview. In: Denzin NK, Lincoln YS, eds. Strategies of qualitative inquiry. Thousand Oaks, Calif: Sage Publications, 1998:158-83.

13. Ritchie J, Lewis J, Elam G. Designing and selecting samples. In: Ritchie J, Lewis J, eds. Qualitative research practice: a guide for social science students and researchers. London: Sage 2003, 2003:77-108.

14. Heatherton TF, Kozlowski LT, Frecker RC, et al. The Fagerström Test for Nicotine Dependence: a revision of the Fagerström Tolerance Questionnaire. Br J Addict 1991;86:1119-27.

15. Maskrey V, Blyth A, Brown TJ, et al. Self-help educational booklets for the prevention of smoking relapse following smoking cessation treatment: a randomized controlled trial. Addiction 2015;110:2006-14

16. Graham AL, Papandonatos GD, Cobb CO, et al. Internet and telephone treatment for smoking cessation: Mediators and moderators of short-term abstinence. Nicotine Tob Res 2015;17:299-308.

17. McClure JB, Bricker J, Mull K, et al. Comparative-effectiveness of group-delivered acceptance and commitment therapy vs. Cognitive behavioral therapy for smoking cessation: A randomized controlled trial. Nicotine Tob Res 2018 (Published Online First: 28 Dec 2018).

18. Nieva G, Comín M, Valero S, et al. Cigarette dependence and depressive symptoms as predictors of smoking status at five-year follow-up after a workplace smoking cessation program. Addict Behav 2017;73:9-15.

19. Glaser BG. Theoretical sensitivity: advances in the methodology of grounded theory. Mill Valley, Calif.: Sociology Press, 1978.

20. Nagle B. Qualitative Data Tool: Using QDA Miner Lite Association For Instuitional Research. Data and Decisions for Higher Education https://www.airweb.org/eAIR/techtips/Pages/QDA-Miner-Lite.aspx (Accessed 27 Jan 2018).
21. Hughes JR, Solomon LJ, Naud S, et al. Natural history of attempts to stop smoking. Nicotine Tob Res 2014;16:1190-8.

22. Twyman L, Bonevski B, Paul C, et al. Perceived barriers to smoking cessation in selected vulnerable groups: a systematic review of the qualitative and quantitative literature. BMJ Open 2014;4:e006414.

23. Wang J, Li C, Jia C, et al. Smoking, smoking cessation and tobacco control in rural China: a qualitative study in Shandong Province. BMC Public Health 2014;14:916.

24. Daily C. China's cigarette culture 2014 [updated Updated: 2014-0109 16:52. http://www.chinadaily.com.cn/china/2014-01/09/content 17226897.htm (Accessed 30 Jun 2018).

25. Ismail S, Mohd Zulkefli NA, Chung CS, et al. Factors influencing smoking behaviour changes during Ramadan among Malay male students. Journal of Fasting and Health 2015;3:97-102.

26. Abu Bakar AM JL, Nasir AM, Anselm ST, et al. Religious belief in relation to smoking: a cross-sectional study among Muslim males in the month of Ramadan. Malaysian J Med Health Sci 2002;2:32-5.

27. Yong HH, Hamann SL, Borland R, et al. Adult smokers' perception of the role of religion and religious leadership on smoking and association with quitting: a comparison between Thai Buddhists and Malaysian Muslims. Soc Sci Med 2009;69:1025-31.

28. Frieden TR, Blakeman DE. The dirty dozen: 12 myths that undermine tobacco control. Am J Public Health 2005:95:1500-5.

29. Breitling LP, Rothenbacher D, Stegmaier C, et al. Older Smokers' Motivation and Attempts to Quit Smoking: Epidemiological Insight into the Question of Lifestyle Versus Addiction. Deutsches Ärzteblatt International 2009;106:451-5.

30. Stolerman IP, Jarvis MJ. The scientific case that nicotine is addictive. Psychopharmacology (Berl). 1995;117:2-10. discussion 14-20.

31. Henningfield JE, Cohen C, Slade JD. Is nicotine more addictive than cocaine? Br J Addict 1991;86:565-9.

32. Cohen C, Pickworth WB, Henningfield JE. Cigarette smoking and addiction. Clin Chest Med 1991;12:701-10.

33. Hughes JR, Naud S. Perceived role of motivation and self-efficacy in smoking cessation: A secondary data analysis. Addict Behav 2016;61:58-61.

34. Morphett K, Partridge B, Gartner C, et al. Why Don't Smokers Want Help to Quit? A Qualitative Study of Smokers' Attitudes towards Assisted vs. Unassisted Quitting. Int J Environ Res Public Health 2015;12:6591-607.

35. Ministry of Health Malaysia Academy of Pharmacy Malaysia. Clinical practice quidelines on treatment of tobacco use disorder Putrajaya. Malaysia: Tobacco Control Unit \& FCTC Secretariat, 2017. Available from. http://www.moh.gov.my/penerbitan/CPG2017/Respiratory/ CPG_TobacoDisorder.pdf. (Accessed 6 Feb 2018). 